6

OPEN ACCESS

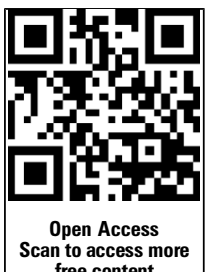

- Additional material is published online only. To view please visit the journal online (http://dx.doi.org/10.1136/ thoraxjnl-2015-207188)

${ }^{1}$ Lane Fox Respiratory Unit, Guy's and St Thomas' NHS Foundation Trust, London, UK ${ }^{2}$ Division of Asthma, Allergy and Lung Biology, King's College London, London, UK ${ }^{3}$ Emergency Department, Guy's and St Thomas' NHS Foundation Trust, London, UK ${ }^{4}$ Department of Acute Medicine, Guy's and St Thomas' NHS Foundation

Trust, London, UK

${ }^{5}$ Division of Health and Social Care Research, King's College London, London, UK

${ }^{6}$ NIHR Respiratory Biomedical Research Unit at the Royal Brompton \& Harefield NHS Foundation Trust and Imperial College, London, UK

\section{Correspondence to} Dr Eui-Sik Suh, Lane Fox Respiratory Unit, St. Thomas' Hospital, Westminster Bridge Road, London SE1 7EH, UK; eui-sik.suh@nhs.net

Received 15 April 2015 Revised 22 June 2015 Accepted 27 June 2015 Published Online First 20 July 2015

\section{SLinked}

- http://dx.doi.org/10.1136/ thoraxjnl-2015-207986 CrossMark

To cite: Suh E-S, Mandal S, Harding $\mathrm{R}$, et al. Thorax 2015;70:1123-1130.

\title{
Neural respiratory drive predicts clinical deterioration and safe discharge in exacerbations of COPD
}

\author{
Eui-Sik Suh, ${ }^{1,2}$ Swapna Mandal, ${ }^{1,2}$ Rachel Harding, ${ }^{1}$ Michelle Ramsay, ${ }^{1,2}$ \\ Meera Kamalanathan, ${ }^{1}$ Katherine Henderson, ${ }^{3}$ Kevin O'Kane, ${ }^{4}$ Abdel Douiri, ${ }^{5}$ \\ Nicholas S Hopkinson, ${ }^{6}$ Michael I Polkey, ${ }^{6}$ Gerrard Rafferty, ${ }^{2}$ Patrick B Murphy, ${ }^{1,2}$ \\ John Moxham, ${ }^{2}$ Nicholas Hart ${ }^{1,2}$
}

\section{ABSTRACT}

Rationale Hospitalised patients with acute

exacerbation of COPD may deteriorate despite treatment, with early readmission being common.

Objectives To investigate whether neural respiratory drive, measured using second intercostal space parasternal muscle electromyography (EMG $G_{\text {para }}$ ), would identify worsening dyspnoea and physician-defined inpatient clinical deterioration, and predict early readmission. Methods Patients admitted to a single-site university hospital with exacerbation of COPD were enrolled. Spirometry, inspiratory capacity (IC), EMG para, routine physiological parameters, modified early warning score (MEWS), modified Borg scale for dyspnoea and physiciandefined episodes of deterioration were recorded daily until discharge. Readmissions at 14 and 28 days post discharge were recorded.

Measurements and main results 120 patients were recruited (age $70 \pm 9$ years, forced expiratory volume in $1 \mathrm{~s}$ $\left(\mathrm{FEV}_{1}\right)$ of $\left.30.5 \pm 11.2 \%\right)$. Worsening dyspnoea, defined as at least one-point increase in Borg scale, was associated with increases in $\mathrm{EMG}_{\text {parammax }}$ and MEWS, whereas an increase in $E M G_{\text {para\%max }}$ alone was associated with physician-defined inpatient clinical deterioration.

Admission-to-discharge change $(\Delta)$ in the normalised value of $E M G_{\text {para }}\left(\triangle E M G_{\text {paramax }}\right)$ was inversely correlated with $\Delta \mathrm{FEV}_{1}(\mathrm{r}=-0.38, \mathrm{p}<0.001)$ and $\Delta \mathrm{IC}(\mathrm{r}=-0.44, \mathrm{p}<0.001)$. $\triangle E M G_{\text {parammax }}$ predicted 14-day readmission (OR 1.13, $95 \% 1.03$ to 1.23 ) in the whole cohort and 28-day readmission in patients under 85 years (OR $1.09,95 \% \mathrm{Cl}$ 1.01 to 1.18$)$. Age (OR $1.08,95 \% \mathrm{Cl} 1.03$ to 1.14$)$ and 12-month admission frequency (OR 1.29, 1.01 to 1.66), also predicted 28-day readmission in the whole cohort.

Conclusions Measurement of neural respiratory drive by $E M G_{\text {para }}$ represents a novel physiological biomarker that may be helpful in detecting inpatient clinical deterioration and identifying the risk of early readmission among patients with exacerbations of COPD.

Trial registration NCT01361451.

\section{INTRODUCTION}

Acute exacerbations of COPD (AECOPD) are common, accounting for $12.5 \%$ of emergency admissions in the $\mathrm{UK}^{1}$ with an in-hospital mortality of up to $10 \% .^{2}$ Eighteen percent of patients with AECOPD present to the emergency department with acute hypercapnic respiratory failure ${ }^{3}$ and a further 5\% will develop late respiratory acidosis.
Key messages

What is the key question?

- Can non-invasive measurement of neural respiratory drive identify clinical deterioration and the risk of early readmission in patients admitted with exacerbation of COPD?

What is the bottom line?

- Neural respiratory drive, measured by second intercostal space parasternal muscle electromyography, is a physiological biomarker of worsening breathlessness and physician-defined clinical deterioration in COPD exacerbations, and may predict early readmission.

\section{Why read on?}

- The results of a large physiological observational cohort study are presented, validating a novel physiological biomarker that represents the balance between the load and the capacity of the respiratory muscle pump during exacerbations of COPD.

Twenty percent of hospitalised patients with AECOPD are readmitted within 28 days, ${ }^{4} 5$ and financial penalties are now in operation for acute care hospitals in the UK and USA for readmissions within 30 days. ${ }^{67}$ It is a health economic priority to identify COPD treatment failure promptly and reduce readmissions, and biomarkers that can achieve this will therefore be of significant clinical value.

Previous studies have reported the patient characteristics that predict readmission among hospitalised patients with COPD, ${ }^{2-11}$ but these are limited by their dependence on non-modifiable parameters, rather than on the trajectory of response to treatment. In addition, early-warning scores ${ }^{12}$ often used to track inpatient clinical deterioration and trigger escalation of care, vary in their ability to predict outcomes such as critical care admission and hospital mortality ${ }^{13}$ limiting the usefulness of these approaches.

More advanced physiological measurements of elastic and threshold respiratory load are difficult 
during an acute exacerbation as invasive monitoring of pleural pressure is poorly tolerated. In addition, the measurement of ventilation in flow-limited patients characterised by neuroventilatory uncoupling, as a result of severe hyperinflation, has significant caveats and therefore the non-invasive measurement of neural respiratory drive (NRD), which is a direct reflection of the imbalance between respiratory muscle load and capacity, would be a preferred option. Indeed, NRD as an advanced physiological biomarker, provides a direct measure of the balance between respiratory muscle load and capacity, ${ }^{14}$ and has gained increasing attention in the acute setting. ${ }^{15}$

Recently, surface electromyography (EMG) of the second intercostal space parasternal muscles $\left(\mathrm{EMG}_{\mathrm{para}}\right)$ has been used as a non-invasive alternative to the invasive oesophageal measurement ${ }^{16}$ of NRD in patients with COPD, asthma and cystic fibrosis. $^{15} 17 \quad 18$ Murphy et al ${ }^{15}$ previously showed, in a pilot feasibility study of this technique, that the change in NRD during hospital admission was a biomarker of physician-defined clinical deterioration, and furthermore, change in NRD from admission to discharge identified patients with COPD who were readmitted within 14 days. However, this previous study was in a small group of selected patients with COPD, with the majority of patients having only a single pair of NRD measurements made during their hospital admission.

We therefore hypothesised that, in a large, prospective observational cohort study of patients hospitalised with exacerbation of COPD, changes in daily measurements of NRD between hospital admission and discharge would predict readmission within 14 and 28 days. We further hypothesised that change in NRD would objectively identify worsening dyspnoea and physiciandefined clinical deterioration.

\section{METHODS}

\section{Patients}

The study was approved by the London-Bentham Research Ethics Committee and participants provided written informed consent. The authors registered the study as an observational cohort study (NCT01361451). Patients with a physician diagnosis of acute exacerbation of COPD, defined according to clinical features and basic investigations, ${ }^{1}$, were enrolled within $12 \mathrm{~h}$ of admission to a UK teaching hospital. The requirement for admission was determined by the attending physician. Patients were excluded if they had another cause for their acute admission (eg, acute heart failure, PE), cognitive impairment, active cancer or significant psychosocial factors.

\section{Admission data}

Demographic and anthropometric data were collected. $\mathrm{FEV}_{1}$, FVC and inspiratory capacity (IC) ${ }^{19}$ were measured using a pneumotachometer (3830, Hans-Rudolph, Shawnee, USA) or a handheld spirometer (Micro, Carefusion, Basingstoke, UK) according to international standards. ${ }^{20}$ Symptoms were assessed using the Medical Research Council (MRC) Dyspnoea scale, ${ }^{21}$ the modified Borg scale for dyspnoea $^{22}$ and the COPD Assessment Test (CAT). ${ }^{23}$ Standard physiological observations (respiratory rate, heart rate, oxygen saturation, body temperature and blood pressure) were collected; an aggregate score derived from these was recorded as the modified early warning score (MEWS), according to local protocol.

\section{$\mathrm{EMG}_{\text {para }}$ measurement}

$\mathrm{EMG}_{\text {para }}$ was measured with patients in a semi-recumbent or seated position, as previously described. ${ }^{15}$ After skin preparation, two surface electrodes (Blue Sensor Q, Ambu, St Ives, UK) were placed in the second intercostal spaces, immediately lateral to the sternum. The skin was marked to allow placement of electrodes in an identical position throughout the study. Nasal cannulae connected to a differential pressure transducer (Technical services, Lane Fox Respiratory Unit, London, UK) identified inspiration and expiration phases (figure 1). $\mathrm{EMG}_{\text {para }}$ signals were amplified and sampled at $2 \mathrm{kHz}$ (Dual Bioamp and Powerlab, AD Instruments, Chalgrove, UK). Signals were analysed using Labchart software (AD Instruments) on a personal computer. The peak root mean square $\mathrm{EMG}_{\text {para }}$ activity for each inspiration was averaged over $1 \mathrm{~min}$ of tidal breathing and normalised to a value of $\mathrm{EMG}_{\text {para }}$ obtained during a maximal inspiratory sniff manoeuvre, obtained before each measurement. ${ }^{15}$ Two measures of NRD were derived, including (1) $\mathrm{EMG}_{\text {para\%max }}$, the mean peak inspiratory tidal $\mathrm{EMG}_{\text {para }}$ normalised to the maximal manoeuvre; and (2) NRDI (Neural Respiratory Drive Index), the product of $\mathrm{EMG}_{\mathrm{para} \% \max }$ and respiratory rate. ${ }^{15}$

\section{Study protocol}

$\mathrm{EMG}_{\text {para }}$, modified Borg scale, $\mathrm{FEV}_{1}, \mathrm{FVC}$ and IC were measured at least daily, between admission and medical fitness for
Figure 1 Representative trace of nasal pressure and second intercostal space parasternal electromyogram during tidal breathing in a patient with COPD during an exacerbation. $\mathrm{P}_{\mathrm{np}}$, nasal pressure; $E \mathrm{GG}_{\text {para }}$ parasternal electromyogram; $\mathrm{RMS}_{\text {para, }}$ root mean square of $\mathrm{EMG}_{\text {para. }}$.
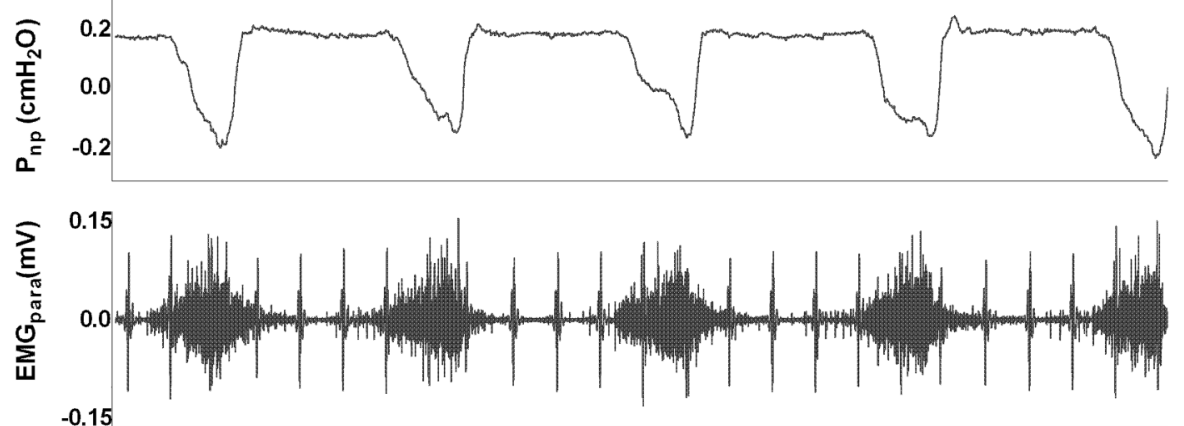

$-0.15$

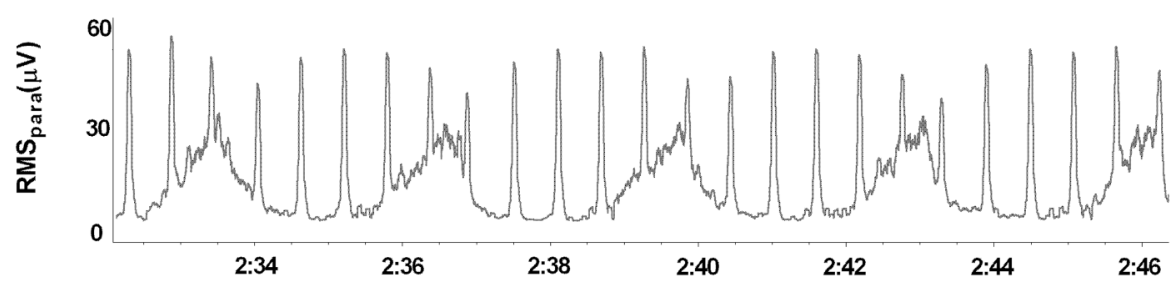

Suh E-S, et al. Thorax 2015;70:1123-1130. doi:10.1136/thoraxjnl-2015-207188 
discharge, and at least $2 \mathrm{~h}$ after the last bronchodilator dose. Medical fitness for discharge was determined by the senior attending physician, which was either senior resident or consultant. Supplemental oxygen was provided as instructed by the attending physicians. Patients were settled at rest for $7 \mathrm{~min}$ before $E M G_{\text {para }}$ traces were acquired for analysis. Patients requiring non-invasive ventilation (NIV) had measurements taken after 10 min off NIV. The attending physicians, who were blinded to $\mathrm{EMG}_{\text {para }}$ data, were asked to provide an opinion regarding clinical improvement or deterioration between successive assessments. EMG $_{\text {para }}$ data were analysed after patients' discharge from hospital. Data for readmissions and deaths were obtained from patients and their relatives, and from medical records. Admission-to-discharge changes in $\mathrm{EMG}_{\mathrm{para} \% \max }$ and NRDI were expressed as $\Delta \mathrm{EMG}_{\mathrm{para} \% \max }$ and $\triangle \mathrm{NRDI}$, respectively. Changes in $\mathrm{EMG}_{\text {para\%max }}$ and NRDI between consecutive inpatient measurements were denoted $\Delta \mathrm{EMG}_{\mathrm{para} \% \text { max,cons }}$ and $\Delta \mathrm{NRDI}_{\text {cons, }}$, respectively.

\section{Primary endpoint and power calculation}

Although this was an observational cohort study, an a priori primary endpoint of 28-day readmission was taken as this was considered to have major clinical relevance to the current financial penalty systems for readmission in the UK and USA. Secondary endpoints were 14-day readmission and clinical deterioration, defined by (1) at least one-point increase in Borg scale $^{24}$ between consecutive recordings, or (2) attending physician opinion. A sample size of 120 was determined from published pilot data ${ }^{15}$ with a presumed 28 -day readmission rate of $20 \%$ to detect a difference in NRDI of 203/min between readmitted and non-readmitted patients with a power of $80 \%$.

\section{Statistical analysis}

Paired data were analysed using $\mathrm{t}$ or Wilcoxon signed-rank tests. Readmitted and non-readmitted groups were compared using independent $t$ or Mann-Witney $U$ tests. Death after discharge without early readmission was analysed together with readmissions. Logistic regression and receiver-operator characteristic (ROC) analyses were used to identify, and test the utility of, predictors of readmission. Kaplan-Meier plots and log rank tests were used to analyse time to readmission. Generalised linear mixed model (GLMM) analyses were used to assess the association between $\Delta \mathrm{EMG}_{\mathrm{para} \% \text { max }}$ cons and episodes of worsening dyspnoea or with physician-defined deterioration. For the purposes of this study, death was analysed with the readmission data.

\section{RESULTS}

\section{Admission, clinical course and readmission data}

A total of 131 patients were enrolled between January 2011 and September 2013 (see online supplementary figure E1), and 120 patients completed the study between admission and discharge (table 1). Twenty (16.7\%) patients were unable to perform $\mathrm{FEV}_{1}$ and FVC manoeuvres at admission, while 27 $(22.5 \%)$ patients could not perform admission IC manoeuvres. Three $(2.5 \%)$ patients declined arterial blood gas sampling. Eight $(6.7 \%)$ patients required NIV or high-dependency care following admission to hospital. There were no patients who received high-flow humidified oxygen therapy. A further three (2.5\%) patients deteriorated more than $12 \mathrm{~h}$ after admission and required NIV. Median length of hospital stay was 3 (IQR 2-6) days. Median interval from the date of medical fitness for discharge to the date of discharge was 0 (IQR 0-1) days. One patient died 3 days after discharge from hospital.
Table 1 Baseline characteristics at admission to hospital

\begin{tabular}{|c|c|}
\hline \multicolumn{2}{|c|}{ Anthropometrics, smoking and previous exacerbations } \\
\hline Age (years) & $70(9)$ \\
\hline Male (\%) & $58(48.3)$ \\
\hline BMI $\left(\mathrm{kg} / \mathrm{m}^{2}\right)$ & $25.3(7.2)$ \\
\hline Current smokers (\%) & $47(39.2)$ \\
\hline Smoking history (pack years) & $40(25-50)$ \\
\hline Exacerbation frequency (/12 months) & $3(1-5)$ \\
\hline Hospital admission frequency (/12 months) & $1(0-2)$ \\
\hline \multicolumn{2}{|l|}{ Current exacerbation history } \\
\hline Duration of symptoms (days) & $4(2-7)$ \\
\hline Systemic steroids prior to admission (\%) & $26(21.7)$ \\
\hline Antibiotics prior to admission (\%) & $30(25.0)$ \\
\hline \multicolumn{2}{|l|}{ Comorbidities } \\
\hline Ischaemic heart disease (\%) & $34(28.3)$ \\
\hline Cerebrovascular disease (\%) & $13(10.8)$ \\
\hline Hypertension (\%) & $53(44.2)$ \\
\hline Diabetes mellitus (\%) & $20(16.7)$ \\
\hline \multicolumn{2}{|l|}{ Disease severity } \\
\hline GOLD stage $2(\%)^{*}$ & $4(4)$ \\
\hline GOLD stage $3(\%)^{*}$ & $36(36)$ \\
\hline GOLD stage $4(\%)^{*}$ & $60(60)$ \\
\hline MRC dyspnoea grade & $4(4-5)$ \\
\hline \multicolumn{2}{|l|}{ Admission investigations } \\
\hline \multicolumn{2}{|l|}{ Arterial blood gasest } \\
\hline $\mathrm{pH}$ & $7.39(0.06)$ \\
\hline $\mathrm{p}_{\mathrm{a}} \mathrm{CO}_{2}(\mathrm{kPa})$ & $5.82(1.39)$ \\
\hline $\mathrm{p}_{\mathrm{a}} \mathrm{O}_{2}(\mathrm{kPa})$ & $8.83(2.98)$ \\
\hline Bicarbonate $(\mathrm{mEq} / \mathrm{L})$ & $25.7(3.8)$ \\
\hline Base excess (mmol/L) & $0.63(3.1)$ \\
\hline Lactate (mmol/L) & $1.7(1.5)$ \\
\hline \multicolumn{2}{|l|}{ Routine laboratory tests } \\
\hline C-reactive protein $(\mathrm{mmol} / \mathrm{L})$ & $65(100)$ \\
\hline Creatinine $(\mu \mathrm{mol} / \mathrm{L})$ & $72(45)$ \\
\hline Fibrinogen (mmol/L) $\ddagger$ & $4.6(1.5)$ \\
\hline Leucocytes $\left(\times 10^{3} / \mu \mathrm{L}\right)$ & $11.9(4.8)$ \\
\hline Neutrophils $\left(\times 10^{3} / \mu \mathrm{L}\right)$ & $8.4(5.0)$ \\
\hline Eosinophils $\left(\times 10^{3} / \mu \mathrm{L}\right)$ & $0.3(0.7)$ \\
\hline Haemoglobin (g/dL) & $13.8(1.7)$ \\
\hline Platelets $\left(\times 10^{9} / \mathrm{L}\right)$ & $259(87)$ \\
\hline Radiographic consolidation & $25(20.8)$ \\
\hline Length of hospital stay (days) & $3(2-6)$ \\
\hline Deaths within 28 days (\%) & $1(0.8)$ \\
\hline Readmission within 28 days (\%) & $26(21.7)$ \\
\hline Deaths within 14 days (\%) & $1(0.8)$ \\
\hline Readmission within 14 days (\%) & $15(12.5)$ \\
\hline \multicolumn{2}{|c|}{$\begin{array}{l}\text { Mean (SD), Median (IQR) or } \mathrm{N}(\%) . \\
{ }^{*} \mathrm{~N}=100 . \\
+\mathrm{N}=117 \text {. } \\
\mathrm{fN}=68 \text {. } \\
\text { BMI, body mass index; GOLD, Global initiative for chronic Obstructive Lung Disease; } \\
\mathrm{MRC} \text {, Medical Research Council; } \mathrm{P}_{\mathrm{a}} \mathrm{CO}_{2} \text {, arterial partial pressure of carbon dioxide; } \\
\mathrm{P}_{\mathrm{a}} \mathrm{O}_{2} \text {, arterial partial pressure of oxygen. }\end{array}$} \\
\hline
\end{tabular}

Fourteen-day and 28-day readmission rates were $12.5 \%$ and $21.7 \%$, respectively. The single death was analysed with the readmission data.

Early warning scores, symptom scores and physiological data MEWS, modified Borg scale and CAT scores all improved from admission to discharge (table 2). $\mathrm{FEV}_{1}, \mathrm{FVC}$ and IC increased over this period, with a concomitant fall in $\mathrm{EMG}_{\text {para\%max }}$ and NRDI (table 2). 
Table 2 Physiological measurements at admission and discharge

\begin{tabular}{|c|c|c|c|}
\hline & Admission & Discharge & p Value \\
\hline \multicolumn{4}{|l|}{ Spirometry } \\
\hline $\mathrm{FEV}_{1}(\mathrm{~L})^{*}$ & $0.69(0.28)$ & $0.75(0.31)$ & $<0.001$ \\
\hline $\mathrm{FVC}(\mathrm{L})^{*}$ & $1.51(0.56)$ & $1.63(0.54)$ & 0.02 \\
\hline $\mathrm{FEV}_{1} \%$ predicted $(\%)^{*}$ & $30.5(11.2)$ & $33.7(12.2)$ & $<0.001$ \\
\hline $\mathrm{FEV}_{1} / \mathrm{FVC}$ ratio $(\%)^{*}$ & $47.4(12.8)$ & $48.9(13.2)$ & 0.184 \\
\hline $\begin{array}{l}\text { Inspiratory capacity (L)† } \\
\text { Symptom scores }\end{array}$ & $1.39(0.58)$ & $1.56(0.63)$ & $<0.001$ \\
\hline Modified Borg scale & $3(2-5)$ & $2(1-3)$ & $<0.001$ \\
\hline COPD assessment test & $29(24-32.75)$ & $24(17-29)$ & $<0.001$ \\
\hline \multicolumn{4}{|l|}{ Routine observations } \\
\hline $\mathrm{S}_{\mathrm{p}} \mathrm{O}_{2}(\%)$ & $92.6(3.5)$ & $93.4(2.8)$ & 0.024 \\
\hline Temperature $\left({ }^{\circ} \mathrm{C}\right)$ & $36.5(0.6)$ & $36.3(0.5)$ & 0.023 \\
\hline Heart rate (/min) & $97.2(15.8)$ & $84.8(12.9)$ & $<0.001$ \\
\hline Respiratory rate (/min) & $23.1(4.3)$ & $20.4(2.4)$ & 0.024 \\
\hline MEWS & $3(2-5)$ & $2(1-3)$ & $<0.001$ \\
\hline \multicolumn{4}{|l|}{ Parasternal EMG parameters } \\
\hline Sniff (maximum) EMG $(\mu \mathrm{V})$ & $74.8(37.3)$ & $76.5(39.1)$ & 0.35 \\
\hline$E M G_{p a r a} \% \max (\%)$ & $17.4(8.2)$ & $15.8(7.3)$ & 0.017 \\
\hline NRDI (/min) & $372(205)$ & 329 (196) & 0.018 \\
\hline
\end{tabular}

\section{Relationship between NRD, physiological parameters} and dyspnoea

Admission-to-discharge change $(\Delta)$ in $\mathrm{EMG}_{\mathrm{para} \% \max }$ was inversely correlated with $\Delta \mathrm{FEV}_{1}(\mathrm{r}=-0.38, \mathrm{p}<0.001), \Delta \mathrm{FVC}$ $(\mathrm{r}=-0.31, \mathrm{p}=0.003)$ and $\Delta \mathrm{IC}(\mathrm{r}=-0.44, \mathrm{p}<0.001)$ (figure 2). However, there was no correlation between $\Delta \mathrm{EMG}_{\mathrm{para} \% \max }$ and $\Delta$ modified Borg scale, $\triangle \mathrm{CAT}$ score or $\triangle \mathrm{MEWS}$. Increases in $\mathrm{FEV}_{1}$ and IC were independently associated with reductions in $\mathrm{EMG}_{\text {paramax }}$ on multiple linear regression analysis $\left(\Delta \mathrm{FEV}_{1}\right.$ standardised coefficient $\beta=-0.36, p=0.001 ; \Delta \mathrm{IC} \quad \beta=-0.26$, $\mathrm{p}=0.019) . \Delta \mathrm{EMG}_{\mathrm{para} \% \max }$ was weakly correlated with age $(\mathrm{r}=+0.24, \mathrm{p}=0.009) . \Delta$ NRDI was weakly inversely correlated with $\Delta \mathrm{FEV}_{1}(\mathrm{r}=-0.30, \mathrm{p}=0.004), \Delta \mathrm{FVC}(\mathrm{r}=-0.29, \mathrm{p}=0.007)$ and $\triangle \mathrm{IC}(\mathrm{r}=-0.40, \mathrm{p}<0.001)$, as well as with body mass index $(r=-0.27, p=0.005)$. There were no correlations between $\triangle \mathrm{NRDI}$ and $\triangle \mathrm{Borg}$ scale or $\triangle \mathrm{MEWS}$.

\section{Predictors of readmission within 28 days}

Twenty-seven (22.5\%) patients were readmitted or died within 28 days of hospital discharge. Independent sample analysis showed significant differences in age, MRC grade, admission haemoglobin levels, hospital admission frequency in the previous 12 months (admission frequency), $\Delta \mathrm{EMG}_{\mathrm{para} \% \max }$ and $\Delta$ NRDI between readmitted and non-readmitted groups at 28 days (table 3). There were no significant differences in the values of $\mathrm{EMG}_{\text {para\%max }}$ and NRDI at discharge between the two groups. With the exception of the MRC grade, univariate analysis demonstrated that all of these parameters predicted readmission at 28 days (table 4). However, in multivariable stepwise logistic regression analysis, only age and admission frequency predicted 28-day readmission (adjusted OR 1.08, 95\% CI 1.03 to $1.14, \mathrm{p}=0.004$, and adjusted OR $1.29,95 \%$ CI 1.01 to $1.66 ; \mathrm{p}=0.043$, respectively). Change in $\mathrm{EMG}_{\mathrm{para} \% \max }$ between admission and discharge did not predict 28-day readmission in the whole cohort. The rate of radiographic
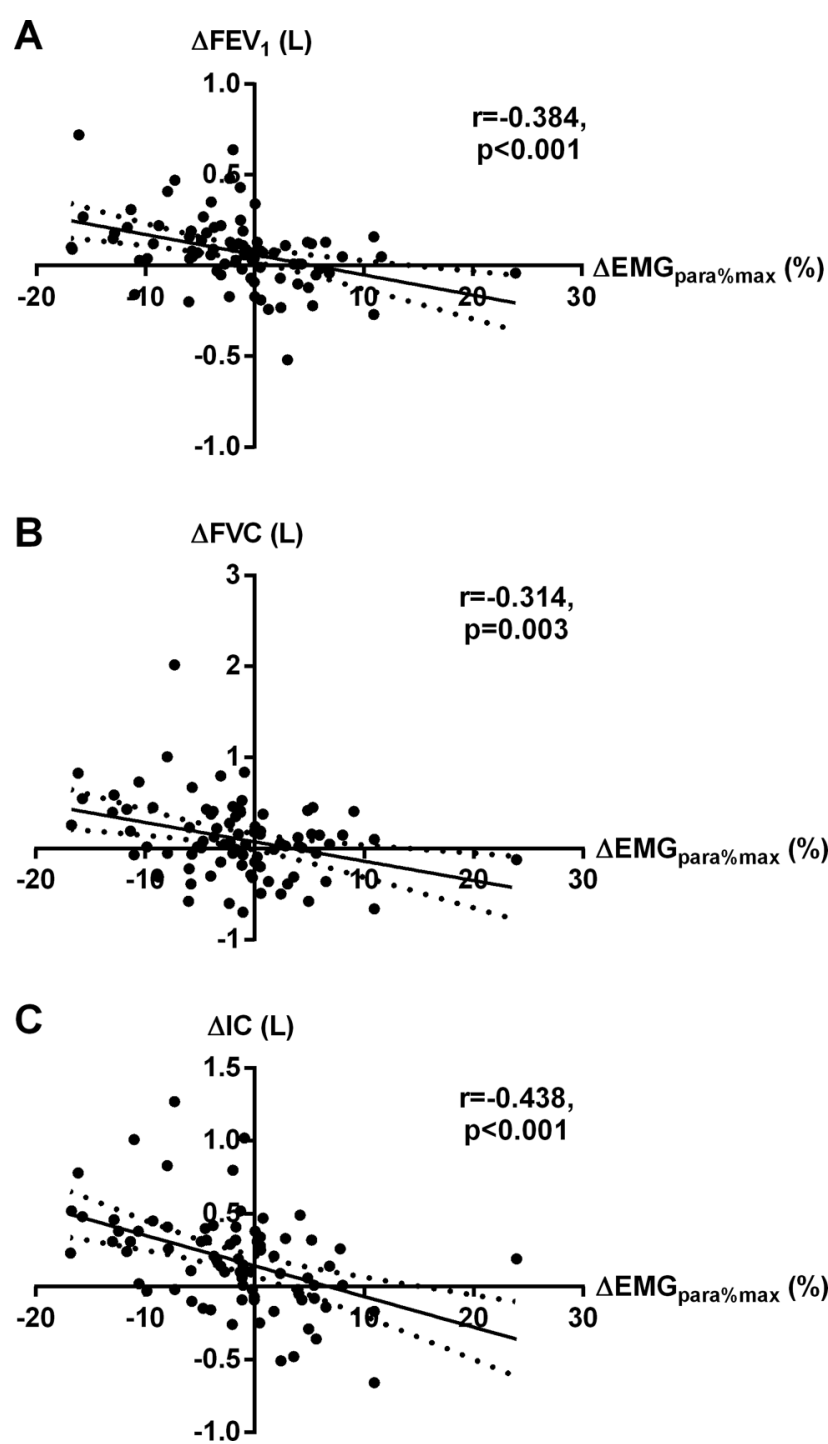

Figure 2 Relationship between admission-to-discharge change

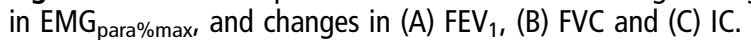
$E M G_{\text {para\%max }} 1$ min mean magnitude of rectified inspiratory parasternal EMG activity normalised to a maximal manoeuvre; IC, inspiratory capacity.

consolidation was not significantly different between the two groups $(11.1 \%$ for the readmitted vs $23.7 \%$ for the nonreadmitted group; $\mathrm{p}=0.16$ ).

In accordance with the correlation, albeit weak, between $\Delta \mathrm{EMG}_{\mathrm{para} \% \max }$ and age, a post hoc, exploratory analysis was performed among patients below an arbitrary age cut-off of 85 years $(\mathrm{n}=112)$. There were $23(20.5 \%)$ readmissions within 28 days among these patients. Under these circumstances, older age (adjusted OR 1.10, 95\% CI 1.02 to $1.16 ; \mathrm{p}=0.017$ ) and increasing $\mathrm{EMG}_{\mathrm{para} \% \max }$ between admission and discharge (adjusted OR $1.09,95 \%$ CI 1.01 to $1.18, \mathrm{p}=0.023$ ) were predictive of 28-day readmission. ROC analysis for the prediction of 28-day readmission in patients under 85 years produced an area under the ROC curve (AUC) of 0.70 for age and 0.66 for $\Delta \mathrm{EMG}_{\mathrm{para} \% \max }$.

\section{Predictors of readmission within 14 days}

Sixteen $(13.3 \%)$ patients were readmitted or died within 14 days of discharge. There were differences in MRC grade and 
Table 3 Differences between readmitted and non-readmitted patients within 28 days

\begin{tabular}{|c|c|c|c|}
\hline & $\begin{array}{l}\text { 28-day readmission } \\
\mathrm{N}=27\end{array}$ & $\begin{array}{l}\text { Non-readmitted } \\
\text { at } 28 \text { days } \\
\mathrm{N}=93\end{array}$ & $p$ Value \\
\hline Age (years) & $75(9)$ & $68(9)$ & 0.001 \\
\hline MRC dyspnoea grade & $5(4-5)$ & $4(3-5)$ & 0.013 \\
\hline $\begin{array}{l}\text { Admission frequency } \\
\text { (/12 months) }\end{array}$ & $1(1-3)$ & $0(0-2)$ & 0.006 \\
\hline $\begin{array}{l}\text { Admission haemoglobin } \\
\text { (g/dL) }\end{array}$ & $13.1(1.8)$ & $14.0(1.7)$ & 0.017 \\
\hline$\Delta \mathrm{EMG}_{\text {para\%max }}(\%)$ & $+1.5(8.4)$ & $-2.4(7.2)$ & 0.018 \\
\hline$\Delta \mathrm{NRDI}(/ \mathrm{min})$ & $+28(217)$ & $-64(189)$ & 0.032 \\
\hline$\Delta$ Modified Borg scale & $-2(-2.5$ to -2$)$ & $-1(-3$ to -1$)$ & 0.58 \\
\hline$\triangle$ CAT & $-7(-12$ to 0$)$ & $-5(-9$ to 0$)$ & 0.30 \\
\hline$\Delta$ Respiratory rate $(/ \mathrm{min})$ & $-3.2(5.3)$ & $-2.6(4.0)$ & 0.50 \\
\hline
\end{tabular}

$\Delta \mathrm{EMG}_{\mathrm{para} \% \max }$ between the readmitted and non-readmitted groups (table 5), but MRC grade did not predict 14-day readmission in the univariate logistic regression model (table 6). Only admission-to-discharge increases in $\mathrm{EMG}_{\mathrm{para} \% \max }$ (adjusted OR $1.12,95 \%$ CI 1.03 to $1.21, \mathrm{p}=0.005$ ) predicted 14-day readmission on multivariable stepwise logistic regression analysis. ROC analysis for the prediction of 14-day readmission gave an AUC of 0.70 for $\triangle \mathrm{EMG}_{\mathrm{para} \% \max }$. By contrast, AUC for $\Delta \mathrm{FEV}_{1}$ and $\triangle \mathrm{IC}$ were 0.57 and 0.56 , respectively (figure 3 ). The failure of $\Delta \mathrm{EMG}_{\mathrm{para} \% \max }$ to fall by more than $3.1 \%$ between admission and discharge had a sensitivity of $93.8 \%$ and a specificity of $41.3 \%$ to detect 14 -day readmission, with a positive predictive value (PPV) of $19.7 \%$ and a negative predictive value (NPV) of $97.7 \%$. Again, there was a non-significant difference in the rate of radiographic consolidation between the groups (6.25\% for the readmitted vs $23.1 \%$ for the non-readmitted group, $\mathrm{p}=0.123$ ). Kaplan-Meier analysis showed that patients whose $\mathrm{EMG}_{\mathrm{para} \% \max }$ failed to fall by less than $3.1 \%$ between admission and discharge had a shorter time to readmission than those whose $\mathrm{EMG}_{\text {para\%max }}$ fell by more than $3.1 \%$ (log rank test $\mathrm{p}=0.03$ ) (figure 4).

When $\triangle$ NRDI was used instead of $\Delta E M G_{\text {parammax }}$ in the regression model as a measure of NRD, it also predicted 14-day readmission or death ( $\triangle \mathrm{NRDI}$ : OR $1.003,95 \%$ CI 1.001 to

Table 4 Univariate logistic regression analysis for predictors of 28-day readmission

\begin{tabular}{llll}
\hline & OR & $\mathbf{p ~ V a l u e ~}$ & $\mathbf{9 5 \%} \mathbf{C I}$ \\
\hline Age & 1.09 & 0.002 & 1.03 to 1.15 \\
Hospital admission frequency & 1.35 & 0.013 & 1.07 to 1.71 \\
Haemoglobin & 0.73 & 0.020 & 0.56 to 0.95 \\
$\Delta$ EMG $_{\text {paramax }}$ & 1.08 & 0.022 & 1.01 to 1.15 \\
$\Delta$ NRDI & 1.002 & 0.036 & 1.000 to 1.005 \\
$\Delta$ Modified Borg scale & 1.07 & 0.49 & 0.88 to 1.29 \\
$\Delta$ CAT & 0.98 & 0.82 & 0.93 to 1.03 \\
$\Delta$ Respiratory rate & 0.97 & 0.50 & 0.88 to 1.07 \\
\hline
\end{tabular}

CAT, COPD Assessment Test; $\mathrm{EMG}_{\mathrm{par} \% \max } 1$ min mean magnitude of rectified inspiratory parasternal EMG activity normalised to a maximal manoeuvre; NRDI, neural respiratory drive index.
Table 5 Differences between readmitted and non-survivors and non-readmitted survivors within 14 days

\begin{tabular}{llll}
\hline & $\begin{array}{l}\text { 14-day readmission } \\
\text { or death } \\
\mathrm{N}=16\end{array}$ & $\begin{array}{l}\text { Non-readmitted } \\
\text { at 14 days } \\
\mathrm{N}=104\end{array}$ & p Value \\
\hline MRC dyspnoea grade & $5(4-5)$ & $4(4-5)$ & 0.039 \\
$\Delta \mathrm{EMG}_{\text {paramax }}(\%)$ & $+3.6(8.3)$ & $-2.3(7.2)$ & 0.003 \\
$\Delta \mathrm{NRDI}(/ \mathrm{min})$ & $+71(221)$ & $-61(190)$ & 0.012 \\
$\Delta$ Modified Borg scale & $-0.25(-2$ to 1$)$ & $-1(-3$ to 0$)$ & 0.12 \\
$\Delta$ CAT & $-8.5(-11$ to -2$)$ & $-5(-9$ to 1$)$ & 0.16 \\
$\Delta$ Respiratory rate (/min) & $-2.6(3.5)$ & $-2.8(4.4)$ & 0.87 \\
\hline
\end{tabular}

Values are expressed as mean (SD) or median (IQR).

CAT, COPD Assessment Test; $\mathrm{EMG}_{\text {para\%max }} 1$ min mean magnitude of rectified inspiratory parasternal EMG activity normalised to a maximal manoeuvre; MRC, Medical Research Council; NRDI, Neural Respiratory Drive Index.

1.006, $\mathrm{p}=0.01$ ). ROC analysis for the prediction of 14-day readmission gave an AUC of 0.70 for NRDI.

\section{Detection of in-hospital clinical deterioration}

A total of 475 pairs of consecutive $E M G_{\text {para }}$ data were acquired from the 122 patients who provided at least one pair of analysable data; although 120 patients completed investigations between hospital admission and discharge, two further patients gave at least one pair of analysable data before withdrawal from the study. Patients had a median of three pairs of measurements (range 1-23) between admission and discharge. There were 116 episodes of worsening dyspnoea, defined as at least one-point increase in Borg scale. On univariate GLMM analysis, an increase in MEWS $\left(\triangle \mathrm{MEWS}_{\text {cons }}\right)$ and in $\mathrm{EMG}_{\mathrm{para} \% \max }$ $\left(\Delta \mathrm{EMG}_{\mathrm{para} \% \max , \mathrm{cons}}\right)$ between consecutive recordings was associated with symptomatic deterioration (table 7). Multivariable GLMM analysis showed that $\triangle \mathrm{MEWS}_{\text {cons }}$ (adjusted OR 1.36, $95 \%$ CI 1.01 to $1.84, \mathrm{p}=0.04$ ) and $\Delta \mathrm{EMG}_{\mathrm{para} \% \text { max,cons }}$ (adjusted OR $1.07,95 \%$ CI 1.01 to $1.14, \mathrm{p}=0.027$ ) were independently associated with worsening of dyspnoea. Multivariable GLMM

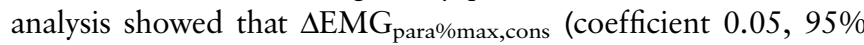
CI 0.01 to $0.09, \mathrm{p}=0.024$ ) and $\Delta \mathrm{IC}_{\text {cons }}$ (coefficient $-1.11,95 \%$ CI -2.19 to $-0.03, \mathrm{p}=0.044$ ) were independently associated with changes in Borg scale of any magnitude between consecutive recordings.

There were 35 episodes of physician-defined deterioration. Only an increase in $\mathrm{EMG}_{\text {para\%max }}$ between consecutive measurements was associated with physician-defined deterioration $\left(\Delta \mathrm{EMG}_{\mathrm{para} \% \max , \text { cons }} \mathrm{OR} 1.030,95 \%\right.$ CI 1.003 to 1.055 , $\mathrm{p}=0.03)$.

Table 6 Univariate logistic regression analysis for predictors of 14-day readmission

\begin{tabular}{llll}
\hline & OR & p Value & 95\% Cl \\
\hline MRC dyspnoea grade & 1.86 & 0.09 & 0.92 to 3.76 \\
$\Delta$ EMG $_{\text {para\%max }}$ & 1.12 & 0.005 & 1.03 to 1.21 \\
$\Delta$ NRDI & 1.003 & 0.014 & 1.001 to 1.006 \\
$\Delta$ Modified Borg scale & 1.23 & 0.10 & 0.96 to 1.57 \\
$\Delta$ CAT & 0.99 & 0.67 & 0.92 to 1.05 \\
$\Delta$ Respiratory rate (/min) & 1.01 & 0.87 & 0.89 to 1.15 \\
\hline
\end{tabular}

Values are expressed as mean (SD) or median (IQR).

CAT, COPD Assessment Test; $\mathrm{EMG}_{\text {para\%max }} 1$ min mean magnitude of rectified inspiratory parasternal EMG activity normalised to a maximal manoeuvre; MRC, Medical Research Council; NRDI, Neural Respiratory Drive Index. 

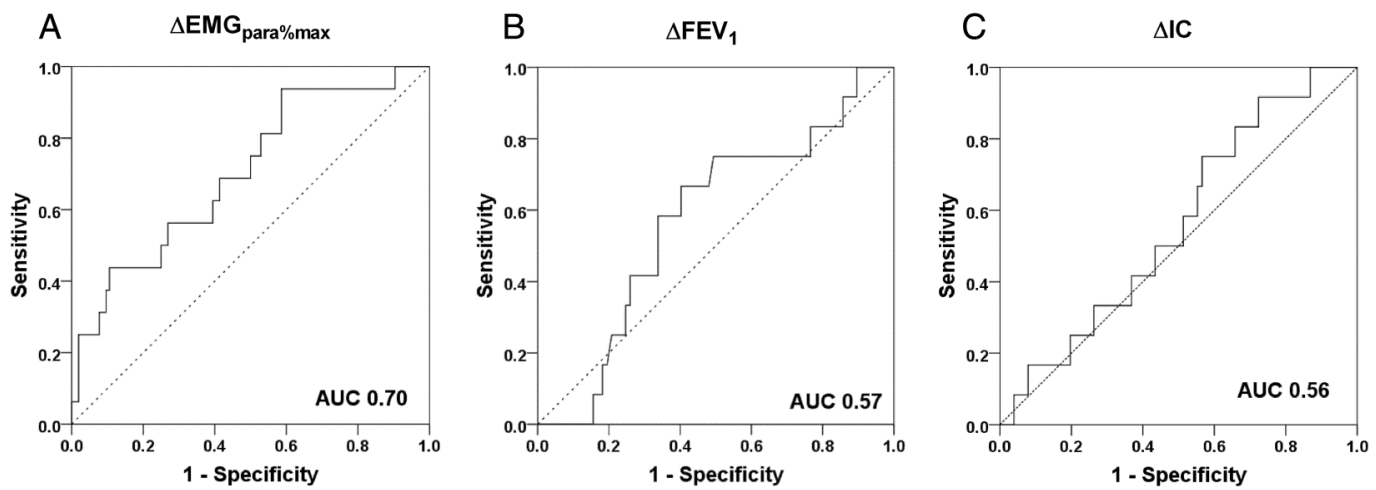

Figure 3 Receiver-operator curves for prediction of 14-day readmission for (A) $\Delta E M G_{\text {para\%max }}$ (B) $\Delta F E V_{1}$, and (C) $\Delta I C$. EMG paramax, 1 min mean magnitude of rectified inspiratory parasternal EMG activity normalised to a maximal manoeuvre; IC, inspiratory capacity; ROC, receiver-operator curve; AUC, area under the receiver-operator curve.

\section{DISCUSSION}

In this single-centre validation study of an advanced physiological biomarker performed in an unselected cohort of acutely unwell patients with COPD, the failure of NRD to fall between admission and discharge predicted readmission within 14 days of discharge. Furthermore, this failure was predictive of readmission within 28 days in those patients under 85 years of age, but not in the cohort as a whole. In addition to the utility of this test to predict clinical outcome following hospital discharge, an increase in NRD between consecutive daily measurements detected episodes of worsening dyspnoea and physician-defined in-hospital clinical deterioration. The physiological rationale of employing NRD was strongly supported by the relationship with change in respiratory muscle physiological load between admission and discharge.

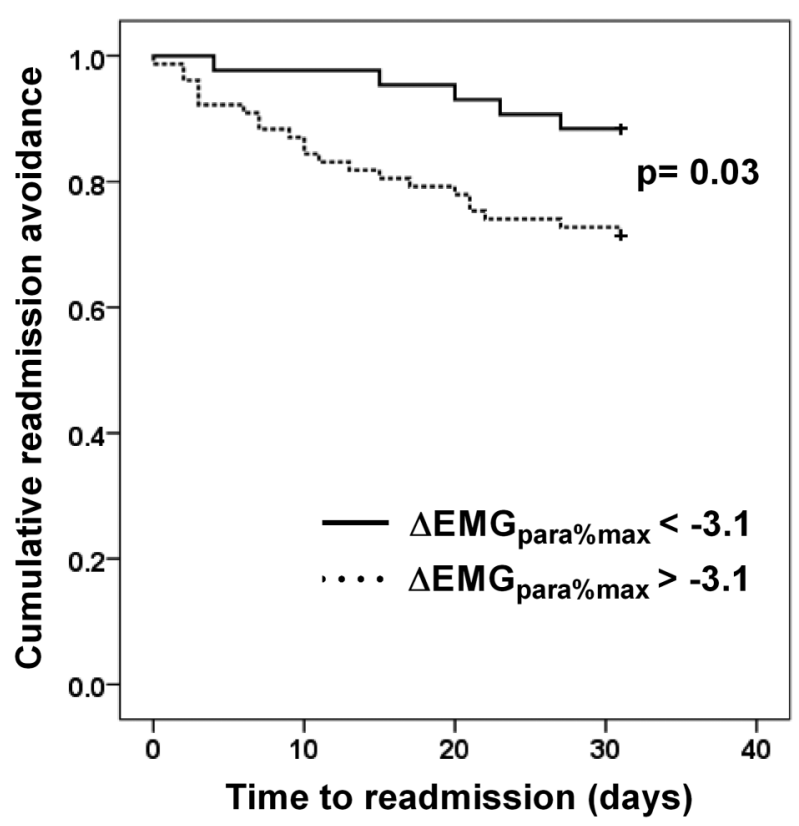

Figure 4 Time-to-readmission Kaplan-Meier plots for patients whose $E M G_{\text {para } \% \text { max }}$ fell by more than $3.1 \%$ between admission and discharge (solid line), and those whose $\mathrm{EMG}_{\text {paramax }}$ fell by less than $3.1 \%$ (dotted line). EMG para\%maxı 1 min mean magnitude of rectified inspiratory parasternal EMG activity normalised to a maximal manoeuvre.

\section{Critique of the method}

Every attempt was made to enrol consecutive eligible patients with a screening to recruitment ratio of 3.4:1 achieved, which is acceptable for such an observational detailed physiological study. Few of the patients enrolled into this study required noninvasive or invasive ventilation at admission, which adds to the generalisability of this study and indeed the current cohort was wholly representative of UK patients admitted to the acute medical wards. ${ }^{2}$ Patients presenting in acute hypercapnic respiratory failure were frequently unable to provide written informed consent, and the study did not have ethical approval for proxy assent and retrospective patient consent.

In line with our previous work, ${ }^{15}$ up to one-fifth of patients were unable to perform forced respiratory manoeuvres at admission, which supports the clinical rationale for non-invasive measurements, such as $E M G_{\text {para }}$, being performed during resting tidal breathing. This could be accommodated into the routine monitoring of acutely unwell patients with COPD as a measure of the respiratory load-capacity balance. The acquisition of respiratory EMG needs to be performed in a standardised manner as variations in electrode position and skin preparation can have a small influence on the magnitude of the signals; however, we have previously published data demonstrating the reproducibility of $\mathrm{EMG}_{\text {para. }}{ }^{15}{ }^{18}$ Although there was variability in the value of the maximal EMG obtained during the sniff procedure between admission and discharge (see online supplementary figure E2), there was no overall increase during the course of the hospital stay and therefore it is unlikely that the reduction in $\mathrm{EMG}_{\mathrm{para} \% \max }$ between admission and discharge was driven by a fall in the maximal $\mathrm{EMG}_{\text {para }}$.

Table 7 Generalised linear mixed modelling analysis for factors associated with clinical deterioration in symptoms as defined by $\geq 1$ point increase in Borg scale

\begin{tabular}{|c|c|c|c|}
\hline & Adjusted OR & p Value & $95 \% \mathrm{Cl}$ \\
\hline$\Delta \mathrm{MEWS}_{\text {cons }}$ & 1.157 & 0.048 & 1.001 to 1.338 \\
\hline$\Delta \mathrm{EMG}_{\mathrm{para} \% \mathrm{max}, \text { cons }}(\%)$ & 1.05 & 0.001 & 1.02 to 1.08 \\
\hline
\end{tabular}




\section{Clinical applicability of the findings}

Readmission within 14 days

Although the cut-off level for $\Delta \mathrm{EMG}_{\mathrm{para} \% \max }$ of $-3.1 \%$ has a low PPV for 14-day readmission, the high NPV indicates that NRD has clinical utility as a risk-stratification tool for patients with COPD being discharged from hospital. Patients whose $\mathrm{EMG}_{\text {para\%max }}$ falls by more than $3.1 \%$ during hospital admission are at very low risk of 14-day readmission and indeed these patients have greater time to readmission. The selected cut-off value is similar in magnitude to the fall in $E \mathrm{MG}_{\mathrm{para} \% \max }$ observed amongst non-readmitted patients in the pilot study of Murphy et $a l,{ }^{15}$ indicating the reproducibility of this technique. Pharmacological and technological therapies could be used in future studies to target a reduction in $\mathrm{EMG}_{\mathrm{para}}$, with the aim of optimising pulmonary mechanics, which could potentially reduce readmission rates. The cut-off value of $-3.1 \%$ requires further prospective validation to become a useful clinical tool.

\section{Readmission within 28 days}

The admission-to-discharge change in NRD failed to predict 28-day readmission across all age groups. This is perhaps unsurprising as several previous studies have shown that age $\mathrm{e}^{25} 26$ and admission frequency ${ }^{827}$ are strongly predictive of readmission. In elderly patients, functional impairment and the burden of chronic disease ${ }^{28}$ play a major role in influencing readmission and, in the current study, it appears to be more influential than the failure to enhance the respiratory muscle load-capacity balance. The current data support the concept that the inpatient trajectory of NRD was a key factor influencing 14-day readmission in all age groups and 28-day readmission in those patients less than 85 years of age. Early readmission, under these circumstances, indicates a failure of the inpatient treatment to modify the airways obstruction and lung hyperinflation, and thereby to ameliorate the respiratory muscle load-capacity balance. Future studies should focus on strategies to modify the load-capacity balance and reduce NRD with the aim of promoting safe discharge. The authors acknowledge the limitations of the post-hoc application of an age cut-off of 85 years and wholly appreciate that this is an exploratory analysis and prospective validation will be required to assess 28-day readmission. However, this does not detract from the potential clinical implications of this approach and this analysis ensures that the appropriate target patient group are recruited into any future trials.

\section{Clinical deterioration during admission}

We have shown that increases in $\mathrm{EMG}_{\text {para }}$ predicted worsening of dyspnoea during hospital admission. NRD has the potential to be used to deliver enhanced monitoring for patients who are either unable to communicate their clinical condition effectively or those who fail to recognise the severity of their symptoms, which is a priority in healthcare systems where clinical resources, in terms of nursing and other clinical personnel, are increasingly being rationed. Although Murphy et $a l^{15}$ found that $\mathrm{EMG}_{\text {para }}$ distinguished between physician-defined improvement and deterioration, this was only in a small number of episodes. We have reproduced these findings in a much larger unselected cohort. Importantly, $\Delta \mathrm{EMG}_{\mathrm{para} \% \max }$ was the only parameter that correlated with physician-defined deterioration, supporting NRD as a physiological biomarker for the early identification of treatment failure.

\section{Physiological validity of NRD in the acute setting}

In this cohort of acutely unwell patients with COPD, we observed a correlation between $\Delta \mathrm{EMG}_{\mathrm{para} \% \max }$ and $\Delta \mathrm{FEV}_{1}$, supporting the hypothesis that $\mathrm{EMG}_{\text {para }}$ reflects the resistive load imposed on the respiratory system during an acute exacerbation. Furthermore, there was a direct relationship between $\Delta \mathrm{EMG}_{\mathrm{para} \% \max }$ and $\Delta \mathrm{IC}$, indicating that changes in the elastic and threshold loads imposed by hyperinflation can be detected by $E M G_{\text {para }}$. It appears therefore, that $E M G_{\text {para }}$ reflects the changes in pulmonary mechanics that accompany an exacerbation of COPD. While the reduction in NRD with decreasing hyperinflation may be due, in part, to the increase in respiratory muscle length, rather than due to a reduction in $\mathrm{NRD},{ }^{29}$ animal studies of parasternal intercostal muscle activation at high lung volume have shown that parasternal muscle EMG tends to remain stable despite acute lung hyperinflation.

\section{CONCLUSION}

During recovery from an acute exacerbation of COPD requiring hospital admission, change in NRD from admission to discharge predicted 14-day readmission in all age groups and 28-day hospital readmission in patients under 85 years old. In addition, change in NRD between successive inpatient measurements was able to detect worsening dyspnoea and physician-defined clinical deterioration. Second intercostal space parasternal EMG is a novel advanced physiological monitoring tool that may be clinically useful in identifying treatment failure during hospital admission and for predicting safe discharge, which is a priority for all acute healthcare organisations.

Contributors Study concept and design: E-SS, PBM, MIP, NSH, GR, JM, NH. Acquisition, analysis or interpretation of data: E-SS, SM, MR, RH, MK, KO, KH, AD and NH. Drafting of the manuscript: E-SS, SM, PBM, NH. Critical revision of the manuscript for important intellectual content: RH, MR, MK, AD, MIP, KO, KH, NSH, GR, JM and NH. Statistical analysis: E-SS, SM, AD. Obtained funding: NH. Administrative, technical or material support: SM, RH, MR, KH, KO, GR. Study supervision: $\mathrm{NH}, \mathrm{JM}$.

Funding E-SS and NH acknowledge funding from Guy's and St Thomas' Charity, and from Philips Research, for the conduct of this study. MIP's contribution to the work was supported by the NIHR Respiratory Biomedical Research Unit at the Royal Brompton \& Harefield NHS Foundation Trust and Imperial College, who part fund his salary. $A D$ acknowledges financial support from the Department of Health via the National Institute for Health Research (NIHR) Biomedical Research Centre Award to Guy's \& St Thomas' NHS Foundation Trust in partnership with King's College London and King's College Hospital NHS Foundation Trust.

Competing interests E-SS was in receipt of an unrestricted educational grant from Philips Research to develop physiological monitoring techniques in patients with COPD. MIP reports personal fees from Philips during the conduct of the study. PBM reports travel fees to conferences, lecture fees and hospitality from Philips Respironics, and hospitality from Resmed. JM has a patent US20130310699 A1 pending to Guy's and St Thomas' NHS Foundation Trust and King's College London. NH reports salary contributions made to Guy's and St Thomas' NHS Foundation Trust from Philips Respironics during the conduct of the study; salary contribution made to Guy's and St Thomas' NHS Foundation Trust, consultancy, lecture fees and unrestricted grants from Philips Respironics outside the submitted work; consultancy, lecture fees and unrestricted grants from Fisher Paykel outside the submitted work: consultancy, lecture fees and unrestricted grants from Resmed outside the submitted work; consultancy, lecture fees and unrestricted grants from B\&D Electromedical outside the submitted work; and lecture fees from Linde outside the submitted work; NH has a patent US20130310699 A1 pending to Guy's and St Thomas' NHS Foundation Trust and King's College London.

Ethics approval London-Bentham Research Ethics Committee.

Provenance and peer review Not commissioned; externally peer reviewed.

Open Access This is an Open Access article distributed in accordance with the Creative Commons Attribution Non Commercial (CC BY-NC 4.0) license, which permits others to distribute, remix, adapt, build upon this work non-commercially, and license their derivative works on different terms, provided the original work is properly cited and the use is non-commercial. See: http://creativecommons.org/ licenses/by-nc/4.0/

\section{REFERENCES}

1 National Institute of Health and Care Excellence. CG101 Chronic obstructive pulmonary disease (update): full guideline. London: National Institute of Health and Care Excellence, 2010. 
2 Steer J, Gibson J, Bourke SC. The DECAF score: predicting hospital mortality in exacerbations of chronic obstructive pulmonary disease. Thorax 2012;67:970-6.

3 Roberts CM, Stone RA, Buckingham RJ, et al. Acidosis, non-invasive ventilation and mortality in hospitalised COPD exacerbations. Thorax 2011;66:43-8.

4 Steer J, Norman EM, Afolabi OA, et al. Dyspnoea severity and pneumonia as predictors of in-hospital mortality and early readmission in acute exacerbations of COPD. Thorax 2012;67:117-21.

5 Royal College of Physicians BTS, British Lung Foundation. Report of the national chronic obstructive pulmonary disease audit 2008: clinical audit of COPD exacerbations admitted to acute NHS trusts across the UK. Royal College of Physicians, 2008.

6 Reducing COPD readmissions - a personal and political priority. Lancet Respir Med 2013:1:347.

7 Burke RE, Coleman EA. Interventions to decrease hospital readmissions: keys for cost-effectiveness. JAMA Intern Med 2013;173:695-8.

8 Garcia-Aymerich J, Farrero E, Felez MA, et al. Risk factors of readmission to hospital for a COPD exacerbation: a prospective study. Thorax 2003;58:100-5.

9 Bahadori K, FitzGerald JM. Risk factors of hospitalization and readmission of patients with COPD exacerbation—systematic review. Int J Chron Obstruct Pulmon Dis 2007;2:241-51.

10 Wong AW, Gan WQ, Burns J, et al. Acute exacerbation of chronic obstructive pulmonary disease: influence of social factors in determining length of hospital stay and readmission rates. Can Respir J 2008;15:361-4.

11 Cao Z, Ong KC, Eng $P$, et al. Frequent hospital readmissions for acute exacerbation of COPD and their associated factors. Respirology 2006;11:188-95.

12 Smith GB, Prytherch DR, Meredith $P$, et al. The ability of the National Early Warning Score (NEWS) to discriminate patients at risk of early cardiac arrest, unanticipated intensive care unit admission, and death. Resuscitation 2013;84:465-70.

13 Gao H, McDonnell A, Harrison DA, et al. Systematic review and evaluation of physiological track and trigger warning systems for identifying at-risk patients on the ward. Intensive Care Med 2007;33:667-79.

14 Moxham J, Jolley C. Breathlessness, fatigue and the respiratory muscles. Clin Med 2009:9:448-52.

15 Murphy PB, Kumar A, Reilly C, et al. Neural respiratory drive as a physiological biomarker to monitor change during acute exacerbations of COPD. Thorax 2011;66:602-8.
16 Luo YM, Moxham J. Measurement of neural respiratory drive in patients with COPD. Respir Physiol Neurobiol 2005;146:165-74.

17 Steier J, Jolley CJ, Polkey MI, et al. Nocturnal asthma monitoring by chest wall electromyography. Thorax 2011;66:609-14

18 Reilly CC, Ward K, Jolley CJ, et al. Neural respiratory drive, pulmonary mechanics and breathlessness in patients with cystic fibrosis. Thorax 2011;66: 240-6.

19 Stevenson NJ, Walker PP, Costello RW, et al. Lung mechanics and dyspnea during exacerbations of chronic obstructive pulmonary disease. Am J Respir Crit Care Med 2005:172:1510-6.

20 Miller MR, Hankinson J, Brusasco V, et al. Standardisation of spirometry. Eur Respir J 2005;26:319-38.

21 Bestall JC, Paul EA, Garrod R, et al. Usefulness of the Medical Research Counci (MRC) Dyspnoea scale as a measure of disability in patients with chronic obstructive pulmonary disease. Thorax 1999;54:581-6.

22 Borg GA. Psychophysical bases of perceived exertion. Med Sci Sports Exerc 1982;14:377-81.

23 Mackay AJ, Donaldson GC, Patel AR, et al. Usefulness of the chronic obstructive pulmonary disease assessment test to evaluate severity of COPD exacerbations. Am J Respir Crit Care Med 2012;185:1218-24.

24 Ries AL. Minimally clinically important difference for the UCSD Shortness of Breath Questionnaire, Borg Scale, and Visual Analog Scale. COPD 2005;2: 105-10.

25 McGhan $R$, Radcliff $T$, Fish $R$, et al. Predictors of rehospitalization and death after a severe exacerbation of COPD. Chest 2007;132:1748-55.

26 Gudmundsson G, Gislason T, Janson C, et al. Risk factors for rehospitalisation in COPD: role of health status, anxiety and depression. Eur Respir J 2005;26: 414-19.

27 Almagro P, Barreiro B, Ochoa de Echaguen A, et al. Risk factors for hospital readmission in patients with chronic obstructive pulmonary disease. Respiration 2006;73:311-17

28 Steer J, Gibson GJ, Bourke SC. Predicting outcomes following hospitalization for acute exacerbations of COPD. QJM 2010;103:817-29.

29 Kim MJ, Druz WS, Sharp JT. Effect of muscle length on electromyogram in a canine diaphragm strip preparation. J App/ Physiol 1985;58:1602-7. 